\title{
NOTA SOBRE GÉNEROS Y COMUNICACIÓN LITERARIA
}

José Domínguez Caparrơs

$U N E D$

A pesar del rechazo que el concepto de género literario sufrió en la teoría de Croce, hoy no se duda de la utilidad de tal noción dentro de los estudios literarios. Podemos recordar, entre otros, los argumentos a favor de tal concepto expuestos por Lázaro Carreter y por Todorov '.

De momento sólo voy a ilustrar uno de los hechos que Lázaro Carreter presenta en apoyo de la realidad del género literario. Se trata de que el escritor sitúa frecuentemente de manera explícita su creación en unas coordenadas genéricas. Así, Valera, que en Las ilusiones del Doctor Faustino se dirige frecuentemente al lector, se cura en salud respecto a la posible falta contra alguna regla del género «novela», cuando dice:

\footnotetext{
«Bien sabe el autor o narrador de esta historia que aquí como en otros pasajes de ella, han de incomodarse los lectores con el héroe principal, de quien exigen en novela una fidelidad y una constancia prodigiosas y a quien han de condenar porque ya amaba a María, ya a Costancita, ya a las dos a la vez, y porque amó durante algunos días a la misma Rosita; pero tire contra él la primera piedra quien en la vida real haya tenido menos variaciones en sus amoresw 2 .
}

1 F. Lázaro Carreter, «Sobre el género literarion, en Estudios de poética, Madrid, Taurus, 1976, pp. 113-120; T. Todorov, *Les genres littéraires», en Introduction a la littérature fantastique, Paris, Seuil, 1970, pp. 8-27.

2 J. Valera, Las ilusiones del doctor Faustino, Madrid, Castalia, 1970 (Clásicos Castalia, 26), pp. 393-394. 
En este mismo sentido, el efecto de realidad perseguido por Daniel Defoe, en Robinson Crusoe, le lleva a la negación retórica del género con el que el lector identifica esta obra sin duda, cuando dice:

\begin{abstract}
*Son tantos los viajeros que han escrito el relato de sus travesías que resultaria bien poco interesante que yo hiciera una detallada narración sobre los lugares donde tocamos puerto, así como de sus habitantes. Dejo esas cosas a otros y remito al lector a los diarios de viaje de algunos ingleses, muchos de los cuales han sido publicados y otros se anuncian frecuentemente* ${ }^{3}$.
\end{abstract}

$Y$, si salimos de la obra de creación y acudimos a comentarios de un autor, no faltan las frecuentes alusiones a hechos que tienen que ver con una caracterización genérica de su obra. Como ejemplo, tomemos las siguientes palabras de Federico García Lorca a propósito de su Romancero Gitano:

\begin{abstract}
«Desde el año 1919, época de mis primeros pasos poéticos, estaba yo preocupado con la forma del romance porque me daba cuenta que era el vaso donde mejor se amoldaba mi sensibilidad. [...] El romance típico había sido siempre una narración y era lo narrativo lo que daba encanto a su fisonomía porque cuando se hacía lírico, sin eco de anécdota, se convertía en canción. Yo quise fundir el romance narrativo con el lírico sin que perdieran ninguna calidad y este esfuerzo se ve conseguido en algunos poemas del Romancero como el llamado Romance sonámbulo [...]* 4 .
\end{abstract}

Si estamos de acuerdo con la licitud de hablar de géneros, cabe seguir preguntándose por el lugar que este concepto ocupa dentro de las disciplinas literarias. El concepto de género, que se identifica con una reiteración de constantes a lo largo de las manifestaciones literarias, y, al mismo tiempo, funciona como un concepto teórico-abstracto clasificador de las obras ${ }^{5}$, tiene que ver con dos disciplinas claramente diferenciadas en la teoría, aunque en la práctica cada vez se ve más la necesidad del mutuo apoyo. Me refiero a la historia literaria y a la teoría literaria.

${ }^{3}$ D. Defoe, Robinson Crusoe, Barcelona, Lumen, 1975 (Ediciones de Bolsillo, 366, 383), II, p. 212.

'F. García Lorca, Prosa, Madrid, Alianza Editorial, 1980 (4.“ edjc.), pp. 51-52.

5 Este carácter abstracto del concepto de género, que logicamente debía ser rechazado por teorías del tipo de la de Croce, queda perfectamente reflejado en las siguientes palabras de E. Bruss:

«Mais on oublie trop souvent qu'on se place, en fait, dans l'abstrait 
A este problema está dedicado el importante y ya clásico trabajo de Viëtor donde, tratando de resolver el problema de si hay que empezar por el establecimiento de unas categorías abstractas (tipos) o por la manifestación histórica del género, dice:

«Le départ en sera une saisie intuitive de l'élément générique à partir des représentants poétiquement les plus significatifs du genre, le pas suivant, qui conduit déjà au tout historique du genre, ramène aux débuts de l'histoire du genre» 6 .

Esta pertenencia del género a la historia y a la teoría literarias se refleja también en distinciones a que se acude a veces dentro de la teoría de los géneros. Pienso, por ejemplo, en la diferenciación entre género -producto de un acercamiento inductivo: observación de un período dado- y tipo - producto del acercamiento deductivo que postula la existencia de géneros literarios a partir de una teoría del discurso literario-; o la diferenciación de géneros teóricos y géneros históricos ${ }^{7}$. Wolf-Dieter Stempel señala que el género tiene que ver a la vez con el sistema -que podemos asimilar a la teoría literaria- y con el habla - que puede asociarse con la historia literaria-, adquiriendo de esta forma un estatuto similar al de la norma en el pensamiento de Coseriu ${ }^{8}$.

Esta situación intermedia es la que hace de los géneros un objeto privilegiado de estudio, y la que está en la raíz del interés actual por ellos, como señala Rainer Warning:

«Certains groupes de discours institutionnalisés font, despuis toujours, et sous l'appellation de genres, l'objet de la théorie littéraire. Et ce n'est

quand on parle de l'intrigue ou du genre d'un texte, et, qui plus est, à des niveaux d'abstraction différents. Ainsi, ce qu'on appelle la valeur générique d'un texte ne se détermine pas de la méme façon que se détermine ce qu'on appelle son style ou sa composition, sa valeur mimétique ou thématique. Elle ne peut se téterminer de la même façon pour la simple raison qu'une intégration totale de la fonction générique aux autres fonctions d'un texte rendrait n'importe quel morceau de litérature sui generis, et tout changement dans le sujet de l'oeuvre ou dans sa structure, aussi infime fûtil, créarait une nouvelle catégorie générique». "L'autobiographie considerée comme acte littéraire», Poétique, 17, 1974, pp. 15-16.

6 K. Viëtor, *L'histoire des genres littéraires*, en Poétique, 32, 1977, p. 505.

O. Ducrot, et T. Todorov, Dictionnaire encyclopédique des sciences du langage, Paris, Seuil, 1972, pp. 193-194; F. Abad Nebot, "Tipo», «norma» y «habla» en literaturaw, en R.S.E.L., 10, I, 1980, p. 196.

W. D. Stempel, «Pour une description des genres littéraires», en Actas del XII Congreso Internacional de Lingüistica y Filología Románica, Bucarest, 1971, Tomo II, p. 568. 
certainement pas par hasard, mais en rapport avec le développement d'une thérie pragmatique du texte, que ce secteur, le plus ancien de la théorie littéraire, a de nouveau suscité un intérêt croissant ces dernières années. En effet, des genres opèrent précissément a la frontière entre la théorie du discours en général et les concrétisations historiques du discours: ".

\section{Y Todorov:}

«Le genre est le lieu de rencontre de la poétique générale et de l'histoire littéraire événementielle; il est à ce titre un objet privilegié, ce qui pourrait bien lui valoir l'honneur de devenir le personnage principal des études littéraires" ".

Parece justificado el afirmar que la forma adecuada de comprender el concepto de género, y de que este concepto sea útil en los estudios literarios, consiste en salir de la obra individual -la obra, única, nos lleva a un relativismo estéril. También parece justificado el afirmar que no conviene quedarse en esquemas meramente teóricos, que recogen dentro de la obra los rasgos que ilustran estas propiedades teóricas, asignadas de antemano a un tipo genérico, y que, por su forzosa generalidad, no explican las normas genéricas reales por las que se rige una obra o un grupo de obras.

El carácter normativo del género se compagina muy bien con una concepción de la literatura como hecho comunicativo en el que no sólo existe un autor, sino que, además, hay un factor tan importante en el funcionamiento literario como es el lector, el público ${ }^{11}$.

La teoría de los actos de lenguaje -en sus aplicaciones a la literatura- y la estética de la recepción insisten en el carácter institucional de la literatura y en la importancia del lector dentro del fenómeno literario ${ }^{12}$.

$\mathrm{Si}$, partiendo de lo dicho anteriormente, concebimos una obra literaria como un hecho comunicativo - con autor, texto y lector- nuestra

9 R. Warning, «Pour une pragmatique du discours fictionnel», en Poktique, 39, 1979, p. 325.

${ }^{10}$ T. Todorov, Les genres du discours, Paris, Seuil, 1978, p. 52.

11 F. Lázaro Carreter, ¿Qué es la literatura? Santander, Publicaciones de la U.I.M.P., 1976. Una aplicación del esquema de la comunicación a la historia de la literatura es la del checo Vodička, según reseñan Ibsch Elrud et D. W. Fokkema, «La théorie littéraire au $\mathrm{XX}^{e}$ siècle», en A. Kibédi Varga (ed.) Théorie de la littérature, Paris, Picard, 1981, p. 44.

12 J. Domínguez Caparrós, «Literatura y actos de lenguaje», en Anuario de Letras, México, XIX, 1981, pp. 89-132; Colectiva, La actual ciencia literaria alemana, Salamanca, Anaya, 1971; T. Todorov, Les genres du discours, cit. 
comprensión de dicha obra tiene que tener en cuenta las normas que rigen el comportamiento de cada uno de estos factores dentro del proceso de la comunicación. Podemos arriesgar la opinión de que son estas normas las que, en definitiva, nos darán las características de un género, y la pertenencia de una obra a un determinado género.

Dentro del pensamiento teórico-literario -es decir, dentro de la disciplina literaria de mayor nivel de abstracción-, cuando se ha tratado de dar una definición del género literario, no se han olvidado las referencias teóricas a cada uno de estos elementos. Veamos, como ejemplo, algunas de las caracterizaciones del concepto de género literario.

Apreciaciones que inciden en el papel del emisor-autor son, por ejemplo, las siguientes:

a) P. Larthomas:

«Si la notion de genre est fondamentale, c'est que chaque genre littéraire répresente, au delà de toutes les autres différences qui sont souvent plus apparentes que réelles, une manière particulière d'utiliser le langage. Qu'est-ce à dire? Que l'auteur (au sens très large du terme), en choisissant tel ou tel genre, choisit une certaine forme, recherche une certaine efficacité, d'une certaine manière; que son texte agit de telle ou telle façon sur un auditeur ou un lecteur qui est dans telles ou telles conditions matérielles ou dans telles ou telles dispositions d'esprit. ${ }^{13}$.

b) Lázaro Carreter, refiriéndose a las coordenadas en las que se sitúa la obra de un escritor, dice que éste:

"Las recibe en forma de propuestas $u$ opciones, $y$ con ellas van, justamente, los géneros literarios, no como meros estímulos del ánimo, que le muevan a escribir desde un temple espiritual dado y a adoptar la primera persona (lírica), la tercera (narrativa) [Jakobson, 1973:130] o la primera y la segunda alternantes (dramática), sino como configuraciones estructurales bien determinadas, de las cuales sólo podrá zafarse mediante un golpe de genio» ${ }^{14}$.

\section{c) Viëtor:}

${ }^{13}$ P. Larthomas, «La notion de genre litteraire», en P. Guiraud y P. Kuentz, La stylistique. Lectures, Paris, Kliencksieck, 1975, p. 72.

F. Lázaro Carreter, «Sobre el género literario», cit, p. 115. 
«En vertu de leur disposition structurale, des contenus déterminés ont déjà une aptitude naturelle pour le genre du sonnet, de l'élégie ou de l'ode. Les exemples les plus significatifs dans l'histoire des genres montrent que c'est en fonction de tels rapport [...] que se decide l'instinct créateur du poète. [...] Pourquoi une expérience déterminée trouve-t-elle dans un sonnet et non dans une ode sa forme appropriée? Bien sûr, l'instinct du poète sera à méme d'en décider plus facilement que le savoir du théoricien ne saura discerner le problème» $\$$.

d) Carlos Bousoño:

«La poesía es, según la concepción tradicional, un género literario, lo que implica, por parte del autor, voluntad de arte, y por parte del lector, conciencia de que lo que lee es lenguaje imaginario dicho por un yo ficticio" 16 .

Basten estas apreciaciones para destacar que la noción de género se presenta, sin lugar a dudas, a la mente del creador, que es quien decide qué rasgos formales, estructurales, va a adquirir el mensaje que va a emitir. Lógicamente, puede decidir, en muy diversos grados, acercarse o separarse de unas estructuras presentes en obras anteriores.

Si tenemos en cuenta que la manifestación más evidente de la idea de género procede de la repetición de rasgos estructurales en dos o más obras, comprenderemos que sean frecuentes las apreciaciones sobre el concepto de género que se centra en el mensaje, en el texto. Veamos algún ejemplo.

En los orígenes de la teoría literaria del siglo $\mathrm{XX}$, Tomachevski considera los géneros literarios como clases particulares de obras

kque se caracterizan por un agrupamiento de procedimientos alrededor de los procedimientos perceptibles, que llamamos los rasgos de género* ${ }^{17}$.

Lázaro Carreter también señala la unión de género y unas particularidades estructurales en los siguientes términos:

«Esa estructura [la que un escritor da a una obra teniendo en cuenta

15 K. Viëtor, «L'histoire des genres littéraires", cit., p.498.

16 C. Bousoño, Teoría de la expresión poética, Madrid, Gredos, 1970 (5." edic.), I, p. 50.

17 B. Tomachevski, «Thématique», en T. Todorov, (ed.), Théorie de la littérature, Paris, Seuil, 1965, p. 302. 
modelos anteriores], en cuanto tal, consta de funciones dispuestas en un cierto orden y tensión mutua, y están desempeñadas, en el plano del contenido, por ciertos elementos significativos (personajes, por ejemplo, comportamientos, lugares de acción, orientaciones afectivas, etc.), que, aunque puedan ser sumamente diversos en las distintas obras del genero, permiten su reducción a unas pocas categorías funcionales bien diferenciadas" ${ }^{\text {in }}$.

No parece necesario insistir en que el género tiene que concretarse, forzosamente, en unas peculiaridades textuales. Ahora bien, conviene señalar que no toda peculiaridad textual es un rasgo genérico - así llegaríamos a la individualidad de la obra y a la imposibilidad de hablar de género literario, concepto que, como hemos visto, tiene un carácter abstracto-, sino que, como dice Lázaro, estos elementos significativos constituyen un rasgo genérico cuando se pueden reducir a categorias funcionales. $\mathrm{O}$, como señala $\mathrm{E}$. Bruss:

* L'association entre caractéristiques textuelles et identité générique n'est pas naturelle, mais conventionnelle. $[. .$.$] Ce n'est qu'en vertu des rè-$ gles constitutives de la littérature que les caractéristiques d'un texte donné "ont la valeur" de signaux d'une fonction générique donnée. L'autobiographie ne présente aucune caractéristique et méme n'existe pas, en dehors des institutions sociales et littéraires qui la créent et la soutiennent» ${ }^{19}$.

Si tenemos en cuenta que la cuestión de la constitución de un género «es casi una aporía resoluble si se acepta que tal constitución se produce cuando un escritor halla en una obra anterior un modelo estructural para su propia creación» ${ }^{20}$, tendremos que admitir que el receptor del mensaje es un elemento capital, si no el principal, en la configuración del género. En efecto, el escritor funciona antes como lector que como escritor, antes como receptor que como recreador o modificador de unas «configuraciones estructurales bien determinadas» (Lázaro).

Según esto, las palabras y la ejemplificación de Claudio Guillén son de una agudeza ejemplar:

*[El género] arranca de un proceso de agrupación [...]. El Lazarillo a solas no se defendía [...]. El Guzmán conoce un éxito excepcional, pero sus efectos traspasan los límites de una obra única, repercuten en el Lazarillo y dan origen a la idea de un género imitable. He aquí que las dos no-

18 F. Lázaro Carreter, «Sobre el género literario», cit., p. 117.

19 E. Bruss, «L' autobiographie considerée comme acte littérairen, cit., p. 18.

20 F. Lázaro Carreter, «Sobre el género literario», cit., p. 117. 
velas se acoplan en la imaginación o la memoria de los lectores, formando grupo, y que este género rudimentario alcanza algo como una vida propia, sugerente, que incita a la imitación. No es la obra individual $[\ldots]$ la que crea el género, desde luego, sino el lector $\longrightarrow$ el escritor antes de escribir, 0 sea, en cuanto lector $[\ldots]{ }^{21}$.

La denominada «estética de la recepción», al centrarse en el estudio de la literatura a través del destinatario de la obra, concede una gran importancia a la idea de género como conjunto de normas que rigen una correcta comprensión del mensaje por parte del lector. $Y$, al mismo tiempo, concede una gran importancia al receptor como punto de partida en la caracterización del género. Resumir su pensamiento en este punto merecería un trabajo aparte. Ejemplo de por dónde van sus intereses pueden ser las siguientes palabras de Weinrich:

«Creado por Karl Mannheim, el concepto de "horizonte de expectativas" fue introducido en la filología por Hans Robert Jauss, Jauss lo emplea sobre todo para los géneros literarios: la obra literaria que se presenta como perteneciente a un determinado género literario, se coloca en un horizonte de expectativas que se ha formado el lector -el lector culto- por su familiaridad con ese génerow 22 .

\section{Conviene que oigamos las palabras del propio Jauss, en el sentido de que}

«[...] toda obra literaria pertenece a un género, lo que equivale a afirmar pura y simplemente que toda obra supone el horizonte de una expectativa, es decir, de un conjunto de reglas preexistentes para orientar la comprensión del lector (del público) y permitirle una recepción apreciativa» ${ }^{23}$.

Dentro de la teoría literaria española, cito las lúcidas palabras de Carlos Bousoño:

"[...] vamos comprobando que lo "poético" de una novela o de un cuento, o de un poema, de una obra de teatro o un trozo de conversación,

21 Apud F. Abat Nebot, «Sobre la novela picaresca como género literario», Apéndice a su edición de La vida de Lazarillo de Tormes, Madrid, Edaf, 1979, p. 145.

${ }_{22}$ H. Weinrich, «Para una historia literaria del lector», en Colectiva, La actual ciencia literaria alemana, cit., pp. 127-128.

${ }^{23}$ H. R. Jauss, *Littérature médiévale et théorie des genres*, en Poétique, 1, 1970, p. 82. 
no aparece o suele no aparecer más que cuando tal significado lo interpretamos, respectivamente, como "significado de novela" o bien "de cuento", "de poema", etc., pues esa interpretación nos sitúa en una actitud de espera correcta con respecto a lo que va a venir $y$, por tanto, nos pone en situación de "asentimiento". Naturalmente, ello supone en el lector una idea bastante precisa de lo que es cada uno de esos moldes literarios, idea que, por su parte, procede de ciertas convicciones nuestras o elementos cosmovisionarios» ${ }^{24}$.

Visto lo que la teoría literaria puede decir respecto de los factores de la comunicación literaria y su papel en el concepto de género, quiero trazar ahora unas líneas de cómo pueden aprovecharse estas indicaciones en el estudio concreto de una obra o un grupo de obras. Entro, pues, en el terreno de la crítica literaria, del que pueden derivarse algunas indicaciones prácticas para el comentario de textos, en lo que se refiere al tratamiento del estudio del género literario de una obra. Y no es que se trate de una simple aplicación del esquema teórico, pues ya hemos visto que la teoría reconocía un papel fundamental al receptor del mensaje -lo mismo al autor como lector, que al horizonte de expectativas del lector-. La importancia de la recepción - la críticadentro de la teoría de los géneros es evidente en posturas como la de Todorov, cuando propone llamar géneros

«les seules classes de textes qui ont été perçues comme telles au cours de l'histoire. [...] Les témoignages de cette perception se trouvent avant tout dans le discours sur les genres (discours métadiscursif), et, de façon sporadique et indirecte, dans les textes eux-memes* 25 .

Indicado el lugar donde hay que buscar las notas caracterizadoras de un género, y teniendo en cuenta los tres factores básicos de la comunicación literaria, puede proponerse como esquema del estudio del género de una obra el siguiente:

\section{GÉNERO: AUTOR+TEXTO+RECEPTOR}

Es decir, la situación de comunicación literaria particular de cada género estará estudiada cuando se haya descrito el papel de cada uno de los elementos que intervienen en esa situación. Para tal descripción, se puede partir de:

24 C. Bousoño, «Significación de los géneros», en Insula, n. ${ }^{\circ} 281$, abril 1970, p. 14.

25 T. Todorov, Les genres du discours, cit., p. 49. 
METALENGUAJE DE
AUTOR
TEXTO
RECEPTOR

ACERCA DE

AUTOR + TEXTO+ RECEPTOR

AUTOR+ TEXTO+ RECEPTOR AUTOR + TEXTO+ RECEPTOR

Es decir, el estudio de la situación de comunicación literaria propia de un género tiene que servirse del metalenguaje de cada uno de los factores de esa comunicación. Se trata, por supuesto, del metalenguaje referido a la cuestión del género.

$\mathrm{Si}$, idealmente, habría que suponer que, para caracterizar un género, habría que completar todos los apartados, en la práctica el caso más frecuente será el del género descrito de acuerdo con parte del esquema propuesto. Tómese, pues, el cuadro como guía de clasificación de los textos relacionados con esta cuestión.

Veamos ahora unos ejemplos del tipo de observaciones metalingüísticas que habría que tener en cuenta, y de su clasificación según el cuadro anterior.

Pío Baroja, en su obra Juventud, egolatría, escribe:

«Esta vez, en lugar de salirme una novela, me han salido unos comentarios acerca de mi vida.

Como casi todos mis libros, éste me ha aparecido entre las manos sin pensarlo y sin quererlo. Me habían encargado escribir una autobiografía de diez o quince páginas. [...]

Quizá al lector le parezca impropia la petulancia del autor en algunos pasajes; quizá en todos encuentre al autor impertinente y ridiculo. He querido lucir y sacar al aire mi vanidad y mi egotismo para que no me vaya ahogando la tendencia ascetica» ${ }^{26}$.

Aquí, a partir del texto, encontramos información sobre el autor -que escribiría respondiendo al encargo de una autobiografía-; sobre el texto - que no hay que entender como novela, sino como *comentarios acerca de mi vida»-; sobre el lector — que es dirigido en el sentido de la benevolencia a la hora de juzgar los comentarios sobre la vida del autor.

Si leemos el prólogo de Julio Caro Baroja a la edición de esta obra, encontramos las siguientes afirmaciones:

«Al recoger él mismo en sus Páginas escogidas (aparecido poco después) un capítulo de él [de Juventud, egolatría], indica que es obra autobio-

${ }^{26}$ P. Baroja, Juventud, egolatria, Madrid, Taurus, 1977, pp. 20-21. 
gráfica, escrita en parte a requerimiento de su editor de entonces, es decir, mi padre, Rafael Caro Raggio. En parte también lo concibió pensando en la composición de un prólogo para tales páginas. Por último porque un traductor alemán le había pedido unas notas sobre su vida y sus ideas» ${ }^{27}$.

En estas palabras del receptor Caro Baroja encontramos referencias al género de la obra de Pío Baroja. Estas referencias aluden al autor y su intención, que oscila entre autobiografía, prólogo o presentación de sí mismo. Aunque para intentar definir más precisamente el género de la obra de Baroja sería necesario allegar más testimonios de otros receptores, o del autor, estos dos recogidos - del texto y de un receptorpueden servirnos para una primera calificación de la obra en cuestión como «autobiografía o comentario sobre algunos aspectos de su vida».

En La Gaviota, de Fernán Caballero, se define con toda nitidez el género «novela de costumbres» ${ }^{28}$. El texto mismo, pues, da la clave genérica.

Una descripción del género "diario de viaje», se encuentra en el texto de Robinson Crusoe citado al principio. En este caso, el texto también da las claves genéricas, aunque, por una figura retórica de matiz irónico, niegue pertenecer a dicho género.

Ejemplo de comentario del mismo autor sobre su intención, modelo y carácter de su obra, lo constituyen las palabras de García Lorca citadas también al principio.

Por supuesto que los ejemplos dados son sólo indicaciones de por dónde pueden ir las caracterizaciones del género de una obra. Habría que ver qué resultado daría un examen más preciso de todos los puntos señalados.

$Y$ voy a terminar citando las palabras de una persona que no se dedica fundamentalmente a la crítica literaria, ni a la teoría, pero que ilustran perfectamente la actitud del receptor literario. Dice José María de Areilza:

*Al comprar un libro nuevo, el lector habitual lo trata de situar en sus esquemas propios, en su fichero imaginario. Todos tenemos al cabo del tiempo nuestros museos de pensamiento catalogado. Una pieza que se resiste a ser encajada en el complejo entramado que hemos inventado para la simplificación mental, la recibimos con huraño recelo. $Y$ no bien entrado en materia, lo vamos etiquetando provisionalmente con semejanzas, resonancias, paternidades y cotejos. Sacamos a veces de él una buena cita; una anécdota olvidada; una referencia que nos permite arrinconar de momento

27 lbidem, p. 8.

${ }^{28}$ Fernán Caballero, La Gaviota, Madrid, Castalia, 1979 (Clásicos Castalia, n. ${ }^{\circ}$ 95), p. 39. 
el propósito de naturalista que avizora la especie y el género del libro para clavarle, como a las mariposas, alfiler y rótulow.

Estas palabras ilustran perfectamente la recepción de la obra literaria -recordemos los horizontes de expectativas- y la importancia que en tal recepción tiene la clasificación genérica.

29 José M." de Areilza, «Los libros de trabajo», en el diario El País, Suplemento Libros, 3, II, 1980, p. 7. 